
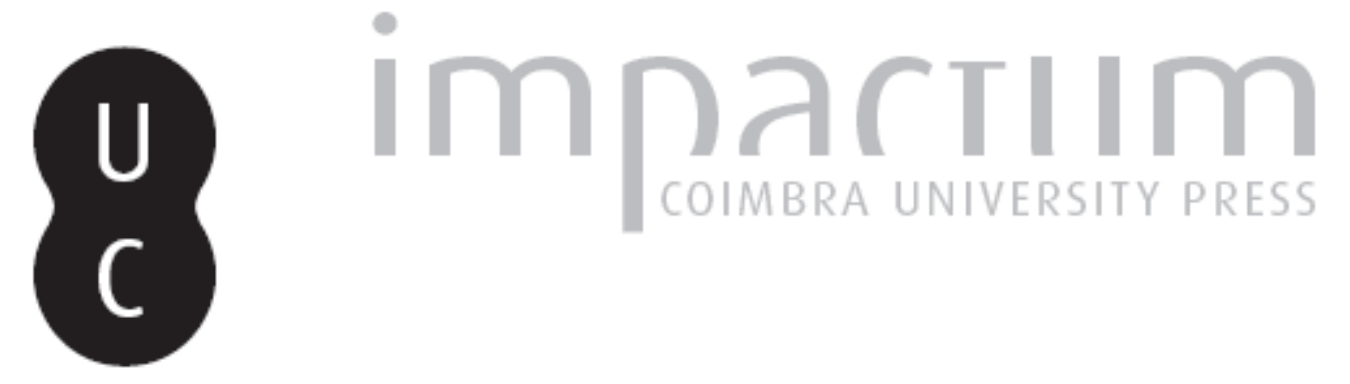

\title{
As «Pedras Vivas» de António Sérgio na construção de uma antropologia
}

Autor(es): $\quad$ Fernandes, Barahona

Publicado por: Imprensa da Universidade de Coimbra

URL persistente:

URI:http://hdl.handle.net/10316.2/45041

DOI:

DOI:https://doi.org/10.14195/2183-8925_5-1_2

Accessed : $\quad$ 26-Apr-2023 07:59:03

A navegação consulta e descarregamento dos títulos inseridos nas Bibliotecas Digitais UC Digitalis, UC Pombalina e UC Impactum, pressupõem a aceitação plena e sem reservas dos Termos e Condições de Uso destas Bibliotecas Digitais, disponíveis em https://digitalis.uc.pt/pt-pt/termos.

Conforme exposto nos referidos Termos e Condições de Uso, o descarregamento de títulos de acesso restrito requer uma licença válida de autorização devendo o utilizador aceder ao(s) documento(s) a partir de um endereço de IP da instituição detentora da supramencionada licença.

Ao utilizador é apenas permitido o descarregamento para uso pessoal, pelo que o emprego do(s) título(s) descarregado(s) para outro fim, designadamente comercial, carece de autorização do respetivo autor ou editor da obra.

Na medida em que todas as obras da UC Digitalis se encontram protegidas pelo Código do Direito de Autor e Direitos Conexos e demais legislação aplicável, toda a cópia, parcial ou total, deste documento, nos casos em que é legalmente admitida, deverá conter ou fazer-se acompanhar por este aviso.

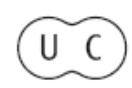




\section{REVISTA DE HISTÓRIA DAS IDEIAS 5}

\section{António Sérgio}

*

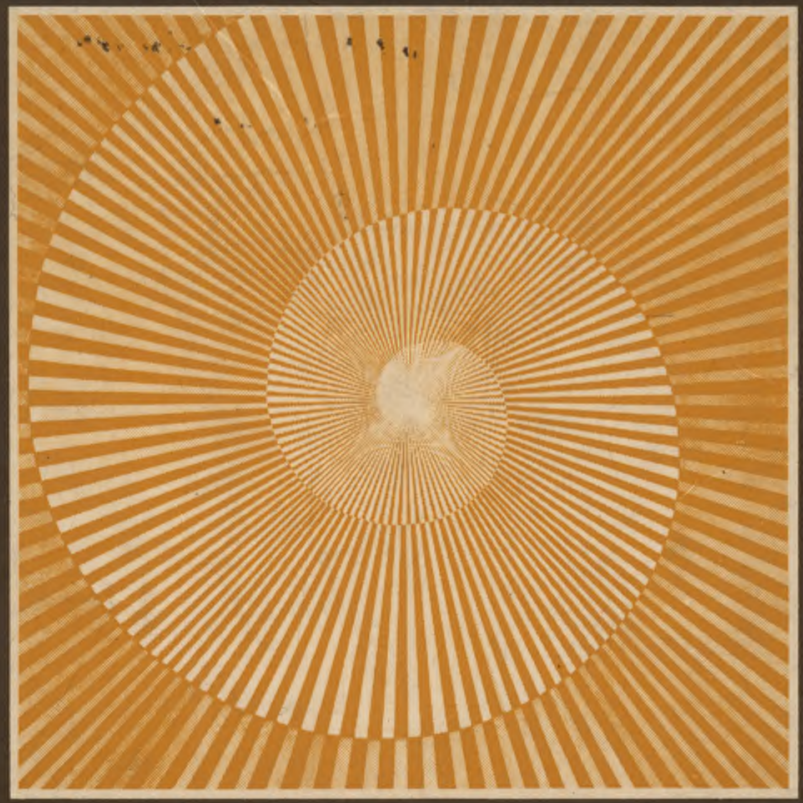

INSTITUTO DE HISTÓRIA E TEORIA DAS IDEIAS FACULDADE DE LETRAS 


\section{AS «PEDRAS VIVAS» DE ANTÓNIO SÉRGIO NA CONSTRUÇÃO DE UMA ANTROPOLOGIA}

Arranque-me a alvorada que nos céus explende a todas as quimeras que me fazem medo! Liberte-me a lei da inteligência clara de todos os fantasmas da imaginação!

\section{Antigona}

O intelecto é um acto de criação infinito, e a percepção é inventada como qualquer teoria cientifica.

\section{Um problema anteriano}

Investigação, atenção, observação, consulta de livros, surgem como instrumentos dos fins humanos, espirituais, morais que interessam o individuo e a comunidade

- dessa Razão cujo princípio é a insígnia do educador, a própria ogiva das aspirações humanas; que é o foco de des-subjectivação e da ascensão do Espírito e que, não se limitando à inteligência do saber científico, não está porém em contradição com ela, por isso que se encontra na raiz comum da objectividade científica e da moral;

------Razão (não só especulativa mas total, espiritual, prática, viva, ou como melhor lhe prefirais chamar é a mesma tendência organizadora, estruturadora, unificadora, (como a razão especulativa) mas abrangendo a totalidade dos factos da consciência - abrangendo, por consequência, o sentimento e a vontade.

Ensaios, «Obras Completas», Tomo I.

* Professor catedrático jubilado de Psiquiatria e Psicologia da Faculdade de Medicina e do Curso de Psicologia da Universidade de Lisboa, de que foi Reitor (74-77). 
A Natureza encarada na sua real unidade, e posta ao serviço da unidade humana.

.... mas acaso não procederá o meu caro Amigo como se os homens existissem para o aperfeiçoamento das coisas, e não as coisas para a dignificação dos homens?

....o Terceiro Homem: o Homem do libertarismo auto-disciplinado e - reformador.

Cartas do Terceiro Homem (l. ${ }^{a}$ Série)

Ao revivenciar os nossos encontros pessoais e revisitar a obra de António Sérgio - ao réfleetir sobre muitas críticas que se lhe faziam e continuam a fazer - emergiu a ideia de que muitas "pedradas» às verdadeiras «pedras vivas» do seu congeminar e agir poderiam ter um fundo significado. Eram afinal um contraponto às apreciações laudatorias - um traço peculiaríssimo da sua fama exceptional e não apenas de valia negativa - o facto de continuar a ser objecto de reflexões críticas como tanto aprazia ao seu espírito. Se se quizer, um esboço de Sérgio hoje. De Sérgio projectado para o futuro.

Em vez de apenas desmontar algumas das «pedras mortas» que jamais faltam a todo o humano edificar, tentaremos neste breve escrito o caminho inverso - encontrar a linha geral que possa ligar as muitas ideias e obras sergianas.

- Será possível apreender traços comuns no seu cogitar de filósofo, no seu compreender de psicólogo, no seu explicar histórico-literário.... e no teorizar e agir de pedagogo, na batalha pela democracia e o cooperativismo?

- Serão possíveis as «vistas» (dito à maneirar-sergiana) do todo, abrangente do «uno» - organizado da sua multifacetada obra? Da sua multidimensional Pessoa?

Adiantando o nosso tentamen, diríamos que essa globalização teve já um começo nas notas $\left(^{\mathrm{x}}\right)$ que temos esboçado sobre a rota da sua psicologia para a epistemologia - no quadro de um humanismo que chamámos «criativo» - e alargaremos agora na perspectiva do que designaremos «antropociências»».

C) A. Silveira, Joel Serrão, David Mourão Ferreira, H. J. Barahona Fernandes, Vasco Magalhães Vilhena, Homenagem a António Sérgio, Lisboa, Academia das Ciências de Lisboa - Instituto de Altos Estudos, 1976. 
Sérgio não foi propriamente um «Mestre» que tivesse fundado uma escola: semeou «ideias» e «formas» de inteligir. Cá no nosso campo especializado (a psicopatologia clínica, dita humana) recebemo-las muito mais como «modelos de cognição» do que ensinanças temáticas, que convicções doutrinárias. Modelos muitos deles apenas indirectos, mediatizando outros problemas em perspectivas homólogas. Motivando porém - o que é essencial - novos esforços inovadores e criativos.

Foi assim que Sérgio marcou a nossa moldagem cultural nos anos 40-60. O esboço seguinte é mais um esforço de compreender Sérgio, na linha da nossa própria experiência da variada «problemática» levantada ao sabor dos encontros pessoais com a sua pessoa e escritos: e depois da sua morte, motivado ainda pela ressurgência de dois dos muitos acontecimentos-chaves da trajectória de Sérgio. Referimo-nos ao abandono não esclarecido, antes das provas (em 1912) do concurso para docente de filosofia da Faculdade de Letras de Lisboa (Nota A) - significando a sua ausência definitiva no ensino universitário no nosso País - uma perda fundamental para a cultura portuguesa.

Referimo-nos ainda à vergonhosa anulação censória da sua entrada para a Academia das Ciências de Lisboa, em 1954, do que se teve conhecimento por António da Silveira $\left({ }^{2}\right)$.

O genial «afinador de intelectos» — paradigma do bem pensar racional e preclaro - tornou-se, por tais e outros eventos da sua acidentada biografia, um libérrimo «agitador de ideias», proclamando a liberdade do espírito como o sumo bem - irmanado com o «bem comum», a educação e o humano governo dos homens, em fraterna e esclarecida cooperação. E acima de tudo envolvendo o «amor intelectual» do vero, do justo e do belo.

- Tão raras e altas virtudes de sagesa não foram consagradas pelas instituições «académicas». Sérgio ficou toda a vida um «livre atirador» do espírito. E parece que ainda continua a sê-lo - nesta paradoxal glória de alimentar a chama perene da crítica - como seria aliás do seu gosto e desejo.

Contestam-no uns tantos pela inconsequência do seu racionalismo, conduzindo a um idealismo extremo que embora crítico, não impede a contaminação misticista.

Fazem-lhe reservas outros pelo entusiasmo utopizante da sua doutrinação democrática-cooperativista. -Afinal não seria insensível a mitologias, mormente económico-políticas....

(2) Idem, ibidem. 


\section{Antonio Sérgio}

Criticamrno ainda outros, apesar da denodada e persistente defesa do social, do «bem comum», pelos liames burgueses, quando não aristocráticos — pelo menos «eleticistas» - enaltecendo (sem os relativizar) os valores supremos do espírito, da autonomia pessoal, do libérrimo pensar anti-dogmático, do sumo bem da liberdade.

Objurgam-no ainda uns tantos pelo cerceamento das suas «vistas» em tudo o que concerne o não claramente consciencializado, as nebulosas intuicionistas, o não formulável em termos cognitivos — os espaços «não luminosos» em que não penetra o seu tão proclamado «dever-ser-racional».

Outros pasmam ante as suas belíssimas alocuções de educador e «afinador» das mentes, afinal posto em causa pelo arroubamento dos seus rompantes polémicos. Ou não compreendem - apenas lida - a sua linguagem hiperbólica, inconfundível e pessoalíssima frente ao apelo da racionalidade, do auto-controle, do desprendimento dos impulsos individuais e das próprias motivações profundas (inconfessadas) de raiz biográfica pessoal.

Cogitemos um tanto. Não serão estas e outras antinomias afinal próprias do humano ser e existir — um esforço imenso da Razão para as superar num nível mais elevado de globalidade unificadora? - a construção possível de uma $\mathrm{An}$ tropologia?

- Tal é a ideia que aqui pomos à vossa crítica, penitenciando-nos pelo incompleto das nossas reflexões.

I - Comecemos por um «ensaio» de certo modo «escolar» e de iniciação psicológica - a sua obra Da Natureza da Afecção ${ }^{3}$ ). Congeminada por Sérgio ainda no ângulo do ensino tradicional da psicologia do começo do século, tratavarse, como ele próprio o intitula, de «um problema posto à psicologia elementarista da consciência». Além da nossa análise já publicada $\left(^{4}\right)$, notaremos, no presente contexto, o seguinte:

A nomenclatura de Sérgio («afecção»), embora clássica e rimando bem com «sensação» não era então nem se veio a tornar usual. Parece ter evitado o equivalente lexicográfico «afeição», porventura pelas suas conotações passionais. O que

O António Sérgio, «Da Natureza da Afeição. - Ensaio de Psicologia e Pedagogia», Revista Americana, Separata n..$^{\circ}$, Ano IV, Rio de Janeiro, Imprensa Nacional, 1913.

$\left({ }^{4}\right)$ Barahona Fernandes, «A Psicologia na Obra de António Sérgio», Revista Portuguesa de Psicologia, n. ${ }^{\circ} 2-3,1975 / 76$. 
é corrente são os termos de cunho não atomístico: afecto, afectividade, emoção, emotividade, sentimentos, etc..

É curioso como em afecção estava implícito o sentido de «perturbação (mórbida)» ainda que no caso se tratasse de um processo genérico, tido por «normal» da vida psicológica (embora muito susceptível de se perturbar mais intensamente, com diversos matizes, já francamente psicopatológicos).

- Mais uma vez Sérgio evidenciava a sua conhecida e mal compreendida propensão racionalista, escotomizando a faceta emotiva que sem dúvida cabe à afecção.

$\mathrm{Na}$ área restricta de tais «vistas» atomísticas, Sérgio caiu assim num impasse e não chegou a lograr a nítida conceptualização das diferenças entre afecção e sensação - distante como estava das correntes fenomenológicas - então nascentes e ainda sem influência sobre os seus estudos e a psicologia prevalecente na época. Devemos no entanto acentuar que no seu sentir e pensar não deixaram de aflorar aquelas feições bem humanas e reais da afectividade, designadas então como «elementos subjectivos» (agrado e desagrado do próprio que as sofre) e que - muito rigorosamente - eram opostas à «referência objectiva» da sensação. Um tal quadro teorético exclusivamente cognitivo não era permeável à compreensão empatizante da estrutura vivencial do acto afectivo (tírnico): a) quer espontâneo e puramente interior «ingénito», dito endotímico; b) quer como resposta à situação e aconteceres compreensíveis e motivantes (afectos reactivos); c) quer noutros níveis de afectos (sentimentos) mais diferenciados e já na ordem valorativa e espiritual, só mais tarde (1923) descritos por Scheler e que depois foram muito utilizados na psicopatologia (K. Schneider) $\left(^{5}\right)$. Talvez, pelo mesmo motivo, não foi sublinhada, por Sérgio, mas é já clara a referência ao sujeito (ainda não fala do «Eu», da interioridade, como mais tarde o fez). Esse referente (o Eu) era, porém, bem explícito na feição de «qualidade subjectiva» que atribuía à afecção. Sabe-se como naquele tempo, por influência da psicologia experimental (de que Sérgio e sua mulher apenas cultivaram os «testes») se procurava evitar «como menos científico» tudo o que não fosse «objectivo» ou «objecti vável».

$\left(^{5}\right)$ Barahona Fernandes, Estruturas do Intelecto segundo as "Cartas de Problemática» de António Sérgio, Memórias da Classe de Ciências da Academia de Ciências de Lisboa, 1969. 
O dilucidar de Sérgio, preso por tais barreiras, esbarrou nesta espécie de «aporia» entre afecção, emoção e sensação.... A afeç̧ão era efectivamente uma vivência muito mais complexa, inabarcável pelos preceitos rígidos do intelectualismo- daquela regra do «partir do elementar para o complexo» a que se tinha obrigado e depois abandonou noutros trabalhos.

Enleado nestes dilemas - que repugnavam à sua claríssima Razão - não voltou ao tema, movido por outros interesses mais aliciantes, como mostraremos. Sentia nele uma questão fechada, melhor, «obscura»: $\quad$ o «sensualismo de Stumpf em matéria de afecção dá-se ao recurso postremo de recorrer às sombras» $\left({ }^{6}\right)$. Tratava-se da famosa «sensação afectiva» de Stumpf que destoava, como ambígua, do esquematismo lógico adoptado. Sente-se já aqui o eco do seu estudo anterior sobre Antero, comentando negativamente os seus aspectos «nocturnos» afectados pela perturbação- emocional da «Razão».

Discutindo, já nos anos 60, o assunto pessoalmente com Sérgio, confirmámos a ideia de que lhe tinham então faltado as contribuições da psicologia Gestalt (que só ulteriormente muito o ocupara) e não se mostrou mais interessado nas conclusões desse estudo, «desquadrado» por completo da sua doutrinação ulterior. Pensamos, no entanto, que pelos aspectos cognitivos constituiu uma primeira tentativa de introdução aos seus ulteriores estudos psicológicos sobre a estrutura do intelecto.

II - Tentemos agora penetrar algo mais na compreensão psicológica da personalidade - do Homem António Sérgio de Souza - do seu próprio sofrimento emocional e na problemática - as antinomias - sempre latentes na sua obra, entre a racionalidade e a emotividade.

No trabalho referido $\left({ }^{7}\right)$ demos já o nosso parecer, como psicopatologista, sobre a crise da «melancolia» de que sofreu na última década da sua vida. Afirmámos então, ao que pensamos com alta probabilidade, que essas e outras crises depressivas (temos notícia de outra crise sofrida cerca de 1919, Nota B) não se exprimem de forma apreciável nos seus textos publicados, ao contrário do que aconteceu nos períodos

C) Loc. cit. (3).

( $\left.{ }^{\mathrm{T}}\right)$ Barahona Fernandes, in loc. cit. (1), pp. 71-122. 
«nocturnos» de Antero. Aventámos então uma interpretação morfo-caracterológica da sua complexa constituição ciclotímica-sensitiva (pág. 91, loc. citJ. Na base deste fundo endotímico peculiar, haveria porventura além das fases mórbidas, leves ondulações afectivas (distimias, disforias, «desânimos» e exaltações) que no decurso dos anos, se acentuaram em vagas mais agudas - de modo mais saliente sob a forma de exaltação hipertímica e hiperestésica - as quais se manifestam de modo reactivo a certas críticas polémicas que o animavam e excitavam de forma exuberante e vivíssima («hiperbólica» como diziam os gregos) - tornando por vezes o aspecto daquilo a que alguém chamou os seus «caprichismos polémicos». Não perdia contudo o controle de si próprio e do seu discorrer e, por mais veemente que fosse, mantinha-se sempre coerente no seu opinar - embora de modo agressivo, por vezes festival ou cáustico, no entusiasmo polémico da luta ardente pelas próprias convicções. São traços «bem humanos», embora muito acentuados numa personalidade peculiar e excepcional.

Recorde-se como desde os tempos da medicina grega se conhecem estas oscilações «temperamentais». Hipocrates explicava-as pelas «discrasias» da bilis - o que em termos modernos significa forte participação somática das perturbações psicológicas $\left({ }^{8}\right)$.

Aliás Platão já conhecia as antinomias das «ideias»e do agir da melancolia e da exaltação hiperbólica de certas pessoas - aquilo a que na filosofia da epoca se chamava «ametria» - a falta da justa medida no ajuizar dos homens.

Digna ainda de nota é a teoria aristotélica da relação entre a genialidade e estas fases da «hipérbole» de certos ho-

$\left.{ }^{8}\right) \mathrm{Na}$ depressão melancólica dita endógena há: a) «sintomas», quer dizer manifestações observáveis de perturbações digestivas, circulatórias, sexuais e muitas outras (tem-se esquecido, a «saburra lingual» dos clássicos e a «enterocolia», etc.); b) o estado de dolência pessoal, de sofrimento subjectivo do próprio enfermo referido à sua corporalidade (não apenas aos órgãos mas ao corpo vivenciado com parte da pessoa); c) e ainda, a interpretações cognitivas feitas pelo doente sobre o significado dessas sensações anormais (até dores) em geral no sentido hipocondríaco (receio ou mesmo conviç̧ão de doenças graves, incapacidades várias, etc.). Referem-se estas noções elementares como contrárias às ideias epocais em discussão, contrastando polar e excessivamente: a natureza «mental» ou a natureza «orgânica do mal». Excluem-se agora as determinantes (a situar noutro plano) nas quais os factores biológicos ingénitos (perturbações bioquímicas encefálicas, etc.) desempenham um papel de relevo em balanço convergente (prevalencendo nos casos endógenos) com as condições ambienciais (psico-sociais e culturais). 
mens, contrapondo-se a outras fases de melancolia. Os elos entre o génio, a «loucura» e a neurose, entre a angústia e a criatividade continuam actualmente a ser discutidos pelos investigadores $\left({ }^{9}\right)$. Queríamos apenas nestes apontamentos analisar a posição de Sérgio ante a obra e a doença de Antero - «os dois Anteros» (o luminoso e o nocturno) ${ }^{10}$ ).

Esta interpretação de Sérgio tem sido muito discutida. Leia-se textualmente: «Dois Anteros», fantasio $\mathrm{Q}^{1}$ ) eu; chamemos-lhe, por comodidade, o Apolíneo e o Nocturno (ou Romântico). Ao primeiro denomino-o espírito crítico do filósofo; ao segundo, o temperamento mórbido do homem. Daqui parte, neste seu primeiro e originalíssimo ensaio - até à malograda «coincidência dos opostos» (pág. 158), ao antinómico fantasiar poético de Antero- cristalizado afinal nas duas imagens: «o luminoso» e «o nocturno».

Sérgio não discrimina expressamente os vários níveis destas trágicas antinomias e finaliza o capítulo com uma bela imagem marítima (como era seu uso), uma imagem sugestiva do naufrágio - talvez alusiva ao suicídio de Antero. Nas cogitações do poeta distingue porém o que chama o espírito crítico na ordem filosófica e o temperamento mórbido na ordem humana. Esta polarização é múltipla e complexa:

1) no plano psicológico: «a lucidez do intelecto, a consciência plena, a concentração da personalidade e da actividade pensante», contrastando com as suas perturbações apenas difusamente descritas: «regiões do vago esquecimento», «dissolução da personalidade», 2) no plano espiritual (sócio-histórico-cultural), por vezes matizado de metáforas poéticas; «a lucidez do intelecto, o heroísmo político, o claro sol» do primeiro; o segundo "canta a noite, o sonho, a submersão, a morte», 3) insiste nesta área no aspecto metafísico (uma filosofia da imanência num, da transcendência noutro) plena de cosmovisões significativas («filosofia intelectualista e aristocrática») exaltante do Amor e da Razão, por uma banda, e, por outra, «humilde fé de obscuras gerações»; até ao extremo

(9) Barahona Fernandes, «A Arte da Medicina e Antropociências», Folia Mediei, Dezembro de 1979, Ciba Portuguesa.

(10) A. Sérgio, Ensaios, «Obras Completas», Tomo IV.

(") Curioso que na primeira edição (1934) figura «imagino» (ioc. cit. p. 280) o que tem um fundo significado na psicologia sergiana. Ouvimo-lo várias vezes insistir que tal actividade não é «imaginação» mas «fantasia». É a sua perene fuga às «imagens» («sentires» representados) e às representações psicológicas imagéticas em favor da criatividade «formal» do espírito. Esta «fuga» parece uma defesa tornada consciente, um esforço de superação até à plena racionalização e racionalidade das «ideias». 
de ter o primeiro «por ideal humano a plena emancipação do espírito adulto», "o segundo muito ao invés, o regresso à irresponsabilidade da criancinha com o refúgio no colo de uma boa mãe» até ao «não ser como um ser adulto», o elogio da morte....

Não alongaremos esta interpretação filosófico-poética da sublime poesia de Antero, na qual o próprio Sérgio viu uma transição (por certo bem peculiar) «de Hegel para Schopenhauer»». Não se pode fugir à hipótese da rejeição íntima da parte de Sérgio da influência do morbus na sua própria Razão, evitando os riscos da repetição de tal processo na sua própria obra.

III - Seja como for, estamos tentando penetrar algo no sentido das suas congeminações altamente racionalizadas e sublimadas. Em suma: compreender Sérgio neste ponto contestado: o exclusivo elogio da Razão, do racional, escotomizando o entendimento da «não razão» (expressão não sergiana) - já não digo da «loucura», mas da «afecção» no seu sentido mais lato - a «sensibilidade» (perturbada) do grande enfermo que foi Antero.

- Como compreender, a falta de «vistas» de Sérgio para a significação humana dos afectos, dos instintos, do pensar intuitivo, do "fundo endotímico» (Nota C) e, em princípio, dos processos psicológicos não racionalizáveis e não consciencializados?

Levantam-se, a propósito, alguns problemas fundamentais: 1) a diversa fenomenologia da doença e estrutura das personalidades destes dois homens geniais; 2) a sua recíproca relação, aliás, no caso, unidirecional — reduzida à relação de Sérgio com Antero personalizado na sua obra metafísica e poética; 3) o ter sido possível no quadro do «dever-ser-racional» de Sérgio, alguns críticos terem inferido a sua não compreensão da emocionabilidade humana.

Diga-se em primeiro lugar, que os «casos» psicopatológicos, e, em consequência, as situações humanas perturbadas) de ambos são muito diversas. Sem discutir o diagnóstico clínico de Antero (apreciado por Souza Martins e Charcot, segundo as ideias da época, como hipocondria, histeria, gastroplegia, etc.) e mais presumivelmente interpretado como psicose maníaco-depressiva por Miller Guerra $\left({ }^{12}\right)-0$ que ressalta no problema posto é que Antero não só sofria de

$\left(^{12}\right)$ J. Miller Guerra, «Patologia de Antero de Quental», Rumo. Fevereiro de 1963. 


\section{Antonio Sérgio}

depressões ansiosas, com feições neuróticas (de expressão somática) mas também de autênticas fases de leve excitação hipomaníaca (sem alcançar um grau psicótico). Enquanto nestas era muito mais intensamente produtivo e activo (campanha cultural e socialista), nas fases depressivas, não deixava por completo de ser criativo. Acontecia deste modo que tanto as vivências de elação efusiva, jubilosa e félicitante das fases expansivas (maniformes) como as vivências de depressão nihilizante, angustiante e trágica da fase contrária, foram efectivamente aproveitadas e elaboradas pelo seu cogitar filosófico e expressas em dramáticos contrastes na sua produção literária.

Ao invés, em Sérgio nada há, de nosso conhecimento na sua obra de prosa publicada que tenha o timbre (tão peculiar e inconfundível) de desespero, da angústia, da subestimação sistemática de si mesmo. Como se disse, pelo menos nas fases depressivas com feição nitidamente patológica, de que temos conhecimento, a sua actividade estava globalmente inibida, impedindo o trabalho mental e todo o combate ideológico e mudando por completo a sua habitual convivialidade e modo de ser conversador, jovial, comunicativo para outras condutas tipicamente «melancólicas» — de desânimo e descrença em si e em tudo que tinha realizado (Nota B).

Nessas fases, em especial na última, (sabe-se de conversas e cartas privadas) considerava-se incapaz, falhado, desvalorizado, dizendo que não entendia como os outros poderiam ter apreciado o que fez é o que escreveu.

Está aqui uma diferença profunda em relação à personalidade de Antero. Em Sérgio o movimento prevalecente deu-se claramente no sentido de desvalorizar como apenas mórbidos os aspectos depressivos - aquilo que o afastava de Antero: («essa lava negra do pensamento apolíneo do nosso vate» Ensaios, t. IV, p. 125), e consequentemente, sobrevalorizar os aspectos inversos: a criatividade esperançosa superlativa da outra fase da doença.

- Será então possível dar uma versão racionalizada (metafisicamente) dessas duas tendências «absolutamente inconciliáveis apesar das diligências do filósofo poeta para intelectualmente justificar o enfermo»?

Com a sua penetração inteligentíssima não passou esta dificuldade despercebida a Sérgio, ao situar no seu devido valor as «influências» e os «influxos» de outros autores (Schopenhauer, E. Hartmann, Hegel e Proudhon); que estas não seriam criadoras mas apenas reveladoras («iluminam coisas que existiam já»). Para nós o que «ilumina» são as tendências próprias do poeta na promoção da sua Pessoa cultural, 
na base do seu temperamento e carácter - dos traços básicos da sua personalidade. Vêm depois os desvios perturbadores expansivos ou deprimente e tudo se ilumina de novo, de novas maneiras, em grau superlativo. $\mathrm{O}$ «génio» está exactamente aqui - em que esses clarões e essas sombras, em vez de distorcer o intelecto (como na maioria dos doentes) tenham, pelo contrário, sido elaborados pelo próprio Antero nas formas sublimadas que há mais de um século se admiram e continuam a fazer-nos reflectir.

Claro que há neste ponto - na generalidade dos casos, além de Antero e de Sérgio- numerosas dificuldades a resolver. É toda a velha questão do nexo entre «o génio e a loucura», ou melhor entre a criatividade excepcional e a tensão e o sofrimento afectivo.

Ainda em vida de Sérgio conversámos sobre este ponto e aceitava que a sua «emotividade» (que confessa em certos escritos) o poderia (como a Descartes) ter impelido e animado, que poderia fazer crescer o empuxo natural para a actividade mental combativa e crítica.

Nunca se mostrou, porém, propenso a aceitar o ponto de vista dos antropólogos da existência, divergindo na época (1952) de Delfim Santos que defendera o «sentido existencial da angústia» $\left({ }^{13}\right)$ na elaboração do projecto da própria existência, mediante a realização da autenticidade do «estar no Mundo».

A desvalorização de Sérgio das áreas obscuras e «nocturnas» da criatividade espiritual veio afinal a rimar com o nosso ponto de vista médico que o Homem perturbado (por exemplo: o melancólico, o neurótico) é uma pessoa que sofre e em consequência das suas inibições (e outras dificuldades) não está só mal «adaptado» à vida e à sociedade, como também limitado na sua real actividade concreta. A perturbabilidade humana vem, na generalidade, a constituir uma minus valia que carece de ajuda e muitas vezes de tratamento médico-psicológico e social. Nos perturbados que sofrem ou fazem sofrer os outros homens há em geral dificuldades na formulação e realização do próprio e do seu mundo pessoal; há regressões para formas de existir e de agir menos livres, menos diferenciadas, menos evoluídas, por vezes «infantis».

Sabemos porém que nas formas menores, ou episódicas (ou assentando em personalidades com traços fortes de carácter, alto nível de intelecto e outras qualidades de inicia-

${ }^{13}$ ) Delfim Santos, Obras Completas, Lisboa, Fundação Calouste Gulbenkian, vol. II, p. 152-165. 
tiva, resistência e criatividade) o perturb ar-se humano pode, pelo contrário, adquirir um valor positivo. E ser não só aproveitado como motivação da psicoterapia de superação da angústia (e da depressão, e da culpa e outras perturbações) mas, ao invés, utilizado como fermento de incitação criativa e mesmo autoconstrutiva da própria Pessoa cultural.

- Seria este o caso de Sérgio? Que além de ter logrado recalcar a recordação penosa e os temas destrutivos da sua(s) primeira(s) crises melancólicas, teve a arte superior de saber utilizar o seu dinamismo emocional («emotividade») como motivante da sua criatividade e motor da sua hiperactividade.

- Era vê-lo, nessas ocasiões, chispando de entusiasmo, declamando o seu congeminar, fantasiar e opinar sobre termas favoritos - em especial quando o contradiziam de modo abrupto e desinteligente. Chegava então fogosamente, a abalar até à derrota, os seus detractores, num discurso agudo, acutilante e ao mesmo tempo festival, por vezes desmesurado, hiperbólico.

- Ao escrever estas linhas estamos a predizer os comentários dos psicologistas freudeanos afirmando convictamente: a alegria, o fogo, a loquacidade crítica de Sérgio não eram mais do que uma fuga a depressão — ou seja um dos «mecanismos psicodinâmicos de defesa» contra o núcleo depressivo dramático e aniquilador que albergava no seu inconsciente. Talvez seja, em parte, mas Sérgio, como é natural, defendia-se de tal interpretação. Sabemos, pelo que confidenciava, que não aceitava e criticava mesmo essa espécie de explicações. Perante o médico, também amigo, em épocas plenamente sadias mostrava-se cauteloso e - no seu tom habitual - dizia-se «ignorante» de tudo isso e muito mais. A sua missão era apenas - como gostava de repetir — uma faina pedagógica de afirmação do espírito e apuramento dos intelectos!

Nesse ponto, sim, se expandia florescente e radioso o seu magnífico intelecto.

IV - As «Cartas de Problemática» (*) foram para nós a plena iluminação do pensar sergiano $\left({ }^{14}\right)$.

Punhamo-las em contraste com o capítulo anterior. Sérgio situa-se agora decisivamente no plano dos processos cognitivos, sem o esforço de superar os aspectos mais «nocturnos» da afectividade e sobretudo do impulso do «i(a)-racional».

(u) Loc. cit. (5). 
$\ddot{\text { E }}$ sabido que presentemente toma relevo uma corrente da psicologia e da psicopatologia que se esforça por integrar cognitivamente vastas áreas da vida psicológica, inclusivé os fenómenos afectivos e suas perturbações.

Nestas «cartas» aos jovens alunos da Faculdade de Ciências, Sérgio analisa, como mostrámos $\left({ }^{15}\right)$, com suma habilidade e vigor, as estruturas do intelecto - aproximando-se das investigações epocais sobre o desenvolvimento da inteligência da escola de Genebra (Piaget e os seus colaboradores).

Revertemos o leitor para esse estudo no qual propusemos a hipótese dos três níveis sucessivos do funcionar do intelecto diferenciados por Sérgio (o sensorial, o percepcional e o formal, ou estritamente científico) poderem ser interpretados como «outras tantas estruturas hierarquizadas da personalidade com acentuação peculiar dos aspectos cognitivos».

Num ângulo psicológico mais especializado, encarámos este cogitar de Sérgio e as reflexões tão pertinentes que sobre ele desenvolve sob várias perspectivas actualizadas: a) a evolutiva, no decurso do desenvolvimento da criança - em franco eco com Piaget; b) a operacional do processar intelectivo, como criador e construtivo; c) a estrutural, marcando bem o seu progresso em relação ao atomismo psicológico e d) a ordenação catégorial dos níveis de actividade, entendidos sempre por Sérgio nos seus aspectos lógico-racionais e suas inferências epistemológicas e metodológicas para a formação produtiva dos alunos.

Desejaríamos agora esboçar uma nova interpretação destas posições sergianas: a sua referência ao todo organizado - à personalidade do Homem em situação no seu Mundo.

Para abreviar o texto, referimos o leitor a outros trabalhos $\left({ }^{16}\right)$ em especial aos modelos de psicologia e psicopatologia do Homem perturbado, que estamos elaborando (Nota C).

Nessa organização integrada de sistemas funcionais tornam-se claras as referências seguintes: 1) das actividades sensoriais (os «sentires» sergianos) e das actividades senso-motoras correlativas: ao sistema da çorporalidade e o seu substracto bio-neuro-psicológico; 2) das actividades percepcionais, ao enlaçamento destas, por mediação do intelecto já constituído, com o Eu (ou Proprium) explicando a vivência do perceber de «algo»; («eu vejo, eu ouço», etc., esta ou aquela figura, um dado som, uma palavra, etc.); 3) das actividades

(15) Idem, ibidem.

(16) Barahona Fernandes, Medicina humana, Lisboa, 1979. 
construtivas propriamente ditas e do intelecto, criando «formas» com validade lógica genérica - referidas à interacção, muito mais complexa de 3) com o que chamamos Pessoa cul-' tural - ou seja o sistema das actividades do Espírito pessoal dando significação, valor e sentido àquilo que é percepcionado, interligando-o com a situação e contexto ambiencial, em especial com a cultura em que o indivíduo está inserido.

Embora pareça, não se trata de «camadas» rigidamente ou «organicamente» concebidas. Antes de «sistemas» em interacções múltiplas reciprocamente enlaçados no conjunto englobante da Personalidade em relação ao seu Mundo.

Como se vê, Sérgio, embora o não diga expressamente, superou aqui francamente o dualismo corpo-alma que também não parecia aceitar no seu «cartesianismo ideal» e admite já a natureza multíplice do real («distinguimos quatro níveis de realidade: material, vital, psíquica e espiritual» $\left({ }^{17}\right)$.

$\mathrm{Na}$ verdade, e dados os seus interesses e intenções, omite quase sempre o «material» (mesmo neste sentido ontológico catégorial). Opõe-se desse modo (ou defende-se contra ele) ao «materialismo» corrente na época - que recusava in limine, mesmo na sua versão dialéctica.

Digna de nota é a diferenciação do psíquico e do espiritual que Sérgio acabou por fazer e nos confirmou em conversa sobre o tema quando the pedimos o seu parecer sobre a adopção dessa distinção, no campo da psicologia e da psiquiatria $\left({ }^{18}\right)$.

Torna-se desde já evidente que o estudo de cada um destes «níveis» cabe a diferentes ciências: 1) as actividades sensoriais (ligando o material e o biológico) dizem respeito à neurofisiologia, psicofisiologia, etc., às «neuro-ciências» em geral; 2) as actividades percepcionais concernem à psicologia s.s.; 3) as actividades «formais» implicam já a lógica, a fenomenologia - tornando-se o ponto de partida para a reflexão epistemológica sobre estas e muitas outras ciências conexas (desde a física da recepção dos estímulos nos órgãos dos sentidos, à bio-física, à bio-química das sinapses entre as células nervosas; desde a biologia geral, a etologia, sócio-biologia, etc., por um lado; e, por outro, os diferentes ramos da psicologia, psicanálise, sócio-psicologia, sociologia e outras ciências humanas e históricas (ditas «do espírito»).

$\left({ }^{1 T}\right)$ A. Sérgio, Ensaios, «Obras Completas», Tomo IV.

(18) Barahona Fernandes, O espirito pessoal em Psiquiatria, in «Actas Luso-Espanolas Neur. y Psiq.», n. ${ }^{\circ} 23$ (2), pp. 93-111, 1964 e «A camada do Espírito», Jornal Médico, 1964, 53, (1106), pp. 829-245. 
$\mathrm{Na}$ visão complexifiçada das actividades do intelecto (o inteligir, o conhecer, compreender, interpretar, explicar) - a todos os níveis - torna-se - em nosso entender - imperativa a "convergência» das ciências naturais e das ciências ditas humanas - melhor, no caso- das ciências culturais.

Dizemo-lo porque, como veremos, somos de parecer que é necessário escolher o Homem como referente comum de todas elas — ou seja dar-lhes uma visão antropológica - visionando-as pois como «antropociências».

Continuando a linha do nosso pensar:

Não ignoramos que Sérgio acentua fortemente neste conjunto o papel da «racionalidade». Já vimos como a contrapõe à emotividade - no caso de Antero, reduzindo-a até quase ao sensível. (Mota D).

Esta antinomia - aliás «demasiado humana» em geral é o calcanhar de Aquiles da epistemologia sergiana. Muitos dos seus críticos visam este alvo, superlativizado até à «inconsequência» de ligar o seu racionalismo com um certo misticismo, também haurido de Antero. Não se esqueça, entretanto, que ambos estavam pelejando contra o reducionismo extremo do naturalismo científico e do positivismo genérico, então prevalecentes e, por outro lado, contra o materialismo filosófíco e até mesmo face fronte a certo «realismo» literário....

- Poderá a perspectiva antropológica, em que nos colocamos, ultrapassar as dificuldades epistemológicas e da própria filosofia de Sérgio?

Não é possível penetrar agora mais profundamente no tema. Pensamos que a face pragmática, a ligação teórico-prática da questão - em especial no que respeita à pedagogia o poderão esclarecer.

No nosso ensaio anterior [loc. cit. 0) pág. 101-107] analisámos a rota de Sérgio: a) por um lado, a partir das ciências - contra a imagética filosofante dos «litera» e contra o dogmatismo espiritualista dos teólogos aristotélico-tomistas e B) por outro lado, frente a outros dogmatismos epocais de colorido marxizante ï) e ainda, usando a reflexão crítica do espírito face ao positivismo e ao empiricismo. Em todas estas frontes tentando harmonizar (nunca ecleticamente) o rigor das formas gerais do conhecimeento racional com a beleza e humanidade das ideias unificadas. (Nota E).

Nos diálogos que nos foi dado ter com Sérgio no último lustro da sua existência até à supressão pela doença da sua criatividade original, fica-nos a ideia de que a sua filosofia ficou, melhor do que incompleta, em aberto. 
Fala neste sentido o facto de sempre se ter recusado à formulação de um «sistema» ou de lhe dar uma organização rígida e sistemática, embora almejasse sempre o «uno». As oportunidades de responder repetidamente aos críticos, despertavam o «moscardo» de Sérgio, discutindo então apenas aspectos focais. (Nota F).

$\mathrm{O}$ que lhe era próprio, e quase específico entre nós, era a defesa constante e estrénua do "filosofar» em fluidez $e$ inventiva, livre de dogmatismos e comprometimentos ideológicos sectários. Pretendia fazê-lo, isso sim, de forma racional, límpida, lançando os seus «faróis» do espírito na «navegação das ideias $\gg . .$. (conforme as suas imagens preferidas que tanto tem desorientado os comentadores apesar da sua racionalidade geométrica e da «beleza» assim encontrada - tal nas artes da marinharia....)

Seja como seja, certo é que só na referida organização do intelecto logrou uma hierarquia catégorial mais sistemática.

$\mathrm{V}$ - Do humanismo criativo na pedagogia para as Antropociências da educação. Para uma Democracia humana.

Não cabe aqui qualquer reexposição das ideias e das propostas pedagógicas de Sérgio, repetidamente propaladas e muito discutidas $\left({ }^{19}\right)$. Limitamo-nos a situar - no contexto proposto - as linhas gerais da sua riquíssima actividade e aliciantes escritos.

O humanismo desta e outras suas obras é um traço quase constante. Quer fale de educação, quer de democracia, do cooperativismo - ou das ciências, da filosofia, da moral-, a feição humana está sempre implícita e com frequência expressa- é o humano que é o referente primacial.

Pense-se bem na sua insistência - desde as «coisas», existindo para o homem, como instrumentos (e não o homem para as coisas, para as máquinas, para as leis, para um sistema ideológico....). Tal o lema que norteia sempre Sérgio vivíssimas alocuções, ensaios e outros trabalhos; e com tal entusiasmo e força de convicção e ao mesmo tempo com tal simplicidade (bem diferente da simpleza) com tal naturalidade e autenticidade que o tornaram, justamente famoso, desde os anos 10-20, em especial pela campanha superiormente humanista da Seara Nova.

$\left({ }^{10}\right)$ Rogério Fernandes, A Pedagogia Portuguesa Contemporânea, Lisboa, Biblioteca Breve, Instituto de Cultura Portuguesa, 1979. 
A posição idealizante do seu socialismo (e da própria, demopedia) moveu-lhe porém a reserva e o afastamento de outros movimentos da esquerda progressista que, dizendo-se também «humanistas», seguiam uma certa linha marxista e depois leninista - da "formação de homens em bases colectivistas», "prontos a sacrificar a liberdade em nome de um objectivo político», subordinando o homem ao Estado $\left({ }^{20}\right)$.

Claro que Sérgio é contrário ao humanismo classicista, do mero culto das línguas antigas, ou do humanismo literário, em especial sentimentalista e romântico. Está porventura mais perto do «neo-humanismo» - da época do iluminismo com o seu colorido idealista - embora muito mais crítico e amplo em Sérgio.

Também neste ponto se situa em Portugal na encruzilhada, já referida, do progresso das ciências naturais positivantes frente ao tradicionalismo histórico. Ou ainda frente aos excessos do tecnicismo pragmático pela reconsideração crítica de vários tipos (terceiro humanismo de W. Jaeger, correntes fenomenológicas, ontológicas existenciais, etc.).

Tratámos já do tema no que se refere ao «Humanismo e Medicina Humana» $\left({ }^{21}\right)$ num estudo dedicado a outra grande figura da cultura portuguesa, Joaquim de Carvalho.

Apesar das origens bem diversas da nossa formação (em convergência dialéctica da fenomenologia com a neuro-fisiologia e da psicopatologia com a patologia cerebral) vivemos com sumo interesse e proveito os «encontros» dialogais com a pessoa e a obra de Sérgio acerca desta problemática.

A Antropologia médica em curso pode ainda beber com proveito das cristalinas águas do ideário sergiano - em especial da sua atitude espiritual de desprendimento e autonomia (claro está - ao passar da doença para a saúde!), de inventiva de hipóteses (a verificar pela «contrastaria» da experimentação), da articulação directa da teoria com a praxis, da humanização das condutas sociais e económicas, da aplicação humanizada das técnicas científicas (quer sejam pedagó-

(*o) Pense-se na oposição de Sérgio a concepções deste tipo actualizadas na obra de G. Smirnov, O Homem Soviético - A formação da personalidade socialista, Trad. Seabra-Dinis, Edições Progresso, Moscovo, 1978.

Autores que navegam em linhas análogas, defendendo outros modos de humanismo socialista têm sempre objectado às suas ideias pedagógicas - que aceitam em princípio como bem humanas, mas criticam nos seus dictamens doutrinários (Sérgio não teria compreendido a luta de classes, a dialéctica, etc.).

$\left.{ }^{\mathrm{M}}\right)$ Barahona Fernandes, «Humanismo e Medicina Humana», Bilbos, vol. 56, 1980. 
gicas, quer terapêuticas - quer de prevenção sanitária, quer de política cooperativista, quer de política da Saúde, quer da política da Cultura e da Educação.

Por estes motivos - e atendendo à actividade do fantasiar ligações entre a verdade, a justiça e a beleza - e a actividade de descobrir novos elos de interacção recursiva entre todos os saberes e a sua valorização humana, de unificar os variegados e contraditórios processos deste trabalho-chamámos humanismo criativo à posição espiritual de Sérgio.

Mais do que o aprofundamento do conceito, interessamos agora a pergunta:

- Sera possível divisar nesta posição já aberta de Sérgio um esboço de antropologia filosófica?

Tomamos a liberdade de apontar para esta outra direcção, do nosso conhecimento, ainda não considerada $\left({ }^{22}\right)$.

Foi a partir deste ângulo que começamos a divisar em Sérgio, que tentamos uma aproximação, não só com a psicologia dos processos cognitivos, mas com correntes modernas de axiomática científica, construtiva e dedutiva, tal se regista na física actual e em novas tendências da psicologia (loc. cit., pág. 109-113).

A perspectiva atrás esboçada de uma ligação antropológica da diversidade multifárica das suas congeminações, vai assim ao encontro do «dever-ser-uno» que repetidamente proclamou mas não ilustrou mais do que em brilhantes ecos neo-platonianos e neo-kantianos.

A seguir tentaremos encontrar estas linhas de construção global a partir de um relance globalizante da pedagogia sergiana.

Assim como ele partiu, no seu dizer, da matemática e da geometria analítica e seguiu ao longo da física, da astronomia e das ciências do mar, assim poderíamos agora indagar as homologias da sua atitude espiritual com as formulações que temos vindo a tentar do referente antropológico das ciências nos seus modos de aplicação e utilização técnica à praxis do homem perturbado - em situação no ambiente nos nossos esforços de superação - para a Saúde.

No que respeita à psiquiatria esquiçámos já uma perspectiva que chamamos «antropocientífica».

A personalidade perturbável que é o Homem (em risco no seu existir no Mundo) e no curso do seu desenvolvimento, desde o nascer ao morrer, situado no ambiente bio-ecológico e no ambiente sócio-histórico-cultural e sujeito a todos os es-

$\left.{ }^{22}\right)$ «Uma linha de cultura pós-sergiana», O Jornal, 9-6-1983. 
tímulos e condições determinantes perturbadores (e patogéneas) pode ser abordada por uma visão multidimensional de diversissimas ciências fundamentais na sua inter- e transdisciplinariedade.

Recordando o modelo resumido na Nota C, enumeremos agora - com o fito à sua integração antropológica e focado no trânsito do «normal» para o «patológico» — os múliplos saberes, métodos e técnicas científicas utilizáveis na apreensão e investigação dos diferentes sistemas funcionais da personalidade: a) as ciências biológicas (genéticas, etc.), bio-ecológicas, físico-químicas podendo ser utilizadas na explicação (e em intervenções profíláticas curativas e recuperadoras) do desenvolvimento dos processos que se operam nas estruturas do organismo; b) de modo comparável estão as ciências da biologia especial (anátomo-fisiologia, neuro-fisiologia e, de um modo geral, as neuro-ciências em relação com os sistemas da corporalidade e da vigilidade; c) com estes últimos ligam-se já a psico-fisiologia e a neuro-biologia molecular, a bio-física, bio-química, etc.; d) com o fundo endotímico-vital enlaçam se também estas últimas e a psicologia geral e certas disciplinas como a etologia, sociologia; e) próximo das estruturas do carácter estão naturalmente os ramos da psicologia, tal a caracterologia e outras; f) do intelecto correspondem as ciências cognitivas, a lógica, matemática e em especial a linguística, etc.; g) claro que a organização do presente na consciência Iinconsciência pode ser apreendida pela fenomenologia vivencial, pela psicanálise e múltiplos ramos da psicologia e psicopatologia; h) bem como também na apreensão, no decurso do desenvolvimento, da estruturação diacrónica do Proprium - o cerne englobante e organizador deste conjunto na constituição do qual convergem os seguintes processos genéticos estruturados: i) da aprendizagem e j) da reactibilidade dinâmica; todo este conjunto é superestruturado finalmente pela k) formação do «espírito pessoal» organizado como Pessoa cultural: com os aportes da sociologia, da história, das ciências políticas, económicas, etc. - da pedagogia, do direito, da axiologia, da estética e outras ciências culturais. Some-se-lhe, em cada nível, as variedades patológicas (desde a fisiopatologia até psicopatologia (não especificadas para não sobrecarregar o texto).

Tal a visão, assim eomplexificada, de uma Antropologia geral multidimensional aplicada às ciências; de uma Antropologia médica do Homem são e doente fundamentando as intervenções da terapia, da prevenção para a Saúde. No ângulo da psicopatologia partimos do Homem como ser perturbável e das «estruturas psicopatológicas básicas» em que 


\section{Antonio Sérgio}

assenta o seu sofrimento, transvios e desvarios - constituindo os modos de ser fundamentais do Homem perturbado que cabe à Medicina psiquiátrica antropológica apreender, «diagnosticar», tratar, cuidar, ajudar e superar (até à Saúde).

- Seria então, como se tem vindo a delinear, lícito usar um modelo homólogo para compreender e explicar as ciências da educação?

Não se trata, desde logo, de um salto catégorial (da ordem normal/patológica para a ordem normativa implicada em todas as intervenções sobre o Homem) porquanto na formação da Pessoa cultural, cúpula da personalidade na situação do homem em sociedade, já estão necessariamente implicados muitos problemas educativos (e neles de ordem etica por um lado, e, por outro, de ordem sócio-económica....).

Em comunicações anteriores sobre o desenvolvimento e aprendizagem feitos no Instituto Piaget delineámos já, em esboço, o seguinte:

- O Homem um ser educável: seria o referente geral de tal perspectiva antropocientífica da pedagogia. É geralmente sabido que o Homem nasce incompleto, deficiente como se disse, e ainda - o que agora mais interessa - ineducado, não formado, inadaptado à vida, carecendo de se desenvolver, de aprender, de se realizar no curso do seu viver no Mundo. Fundamental — em homologia ao que acontece com a sua perturbabilidade superável — é que o Homem seja, como tal, educável - quer dizer com possibilidade de se formar e constituir como Pessoa cultural — quer dizer, organizar em si mesmo e em relação aos outros homens e à sociedade.

Nesta ordem de ideias, propomos usar um modelo homólogo partindo naturalmente dos modelos do desenvolvimento e formação da personalidade. Um tal modelo tem complexas implicações epistemológicas que agora não é possível discutir. Antes de mais, apliquemo-lo à praxis da educação nas diversas idades, desde a primeira infância e tendo em conta as ciências do desenvolvimento que vão desde a organização da Pessoa vital (por interacção genético-ambiencial) até à formação da Pessoa cultural (por interacção de todos os outros sistemas funcionais da personalidade em relação com os pais e restantes familiares, os professores, o ambiente, os grupos, comunidades, etc.).

Estamos portanto face a um modelo «fenomenológico estrutural-dinâmico» do desenvolvimento e criação do Homem com convergência inter - e transdisciplinar de múltiplas ciências centradas na pedagogia — vista não apenas em si mesma, mas na plasticidade de transacções múltiplas activadas com a intenção do Humanum — i.é. uma praxis visando orientar 
ajustar, modelar, enformar, formar e criar - a criança, o jovem, o adolescente, o adulto em contínua evolução até à maturidade, involução e senescência $\left({ }^{23}\right)$.

A finalidade aplicada (à Saúde/Doença) de tal modelo não exclui como é óbvio, o chamado homem «normal» (e suas variantes, crises de desenvolvimento vitais e da existência). Claro que Sérgio se não ocupou desta perspectiva. Serve-nos agora como paradigma para avaliar o problema posto da «colocação das pedras vivas» num modelo análogo aplicável à pedagogia, à democracia, à demopedia.

- Pensamos que, se fomos claros, apesar do esquematismo, se poderá agora entender, sem mais, a posição das «pedras vivas» de Sérgio neste edifício das ciências da educação.

Não se trata de meros ornatos sobre-ajuntados a uma construção já delineada e em edificação.... São efectivamente as pedras básicas e bem vivas neste todo - em vias de se unificar. Notemos, no entanto, que a génese deste perspectivar no decurso dos nossos trabalhos psiquiátricos e do modelo humano assim tão perfunctoriamente esboçado. Trabalhando na psicopatologia, demo-nos conta, tomámo-nos conscientes dos estímulos mediatos e de algumas contribuições directas da obra de Sérgio. Quando esse trabalho avançou, já ele tinha falecido e não mais pudemos ter a luz das suas críticas.

Cremos no entanto que a linha de Sérgio foi neste modelo muito ultrapassada, em especial pela influência de psicólogos (como P. Lersch), de psiquiatras como (H. Ey, K. Schneider e muitos outros) e, em particular, de filósofos das correntes do chamado realismo crítico que Sérgio não chegou a apreender plenamente ou sequer a conhecer (nas suas formas mais conseguidas) como a obra de Nicolai Hartmann e os aportes posteriores da Antropologia $\left({ }^{24}\right)$.

$\mathrm{O}$ espaço não permite agora - como nos cumpria - a análise sistemática dos textos sergianos referidos atrás e a sua inclusão coerente e enquadramento neste conjunto antropológico - tanto na ordem científica como das técnicas e da praxis.

Cremos que a ideia do Homem está sempre presente em toda a obra de Sérgio, tendo como fim último - se o quisermos exprimir no seu estilo: «o dever-ser-humano». Lisboa, 1978 .

(") Barahona Fernandes, Pais de Sousa, Gerontopsiquiatria,

${ }^{(24)}$ Barahona Fernandes, Psychiatrie in S eh st dar Stellung, Bern, Ed. Pongratz - Huber, 1977; N. Hartmann, Neue Wege der Ontologie Ethik; H. G. Gadamer, Vogler, Neue Anthropologie, B. I.-7. Thieme, 1979. 
cendo.

- Tal o colorido sergiano do esboço que estamos te-

Adiantemos mais:- não se trata apenas de meios, de meios humanos - legítimos e desejáveis que também fossem--mas de objectivos «morais» da formação da juventude, dos homens, de todo um povo - o ensinar a pensar de modo efectivo, crítico, criativo- o ensinar a aprender por si e não só aprender memorizando sabença sem sentido. Sérgio lutou por que todo este processo fosse feito em liberdade e em nome da Razão e da Moral - com vista ao «autocontrôlé» de si mesmo, da «auto-governação» e mesmo do auto-desenvolvimento pessoal e grupai — até à criação de uma nova sociedade.

E fazia-o corno acentua Joel Serrão $\left({ }^{25}\right)$ não só na educação mas também nos seus apelos pela formação democrática e cooperativista como o tinha feito nas suas polémicas histórias e literárias.

Claro que este apostolado pedagógico - em contraste e em luta com o que estava acontecendo - focava os homens do seu tempo, primeiro na época da $1 .^{\mathrm{a}}$ República e mais tarde, durante a autocracia salazarista. No dizer de Joel Serrão era um «pedagogismo autonomizado» para a dignificação dos homens.

No nosso modelo esta posição de ensino educativo e formativo situa-se na área e refere-se às actividades do sistema da Pessoa cultural, desprendendo-se (o célebre «desprendimento» sergiano (mal) tido por só idealista das prisões egotistas individuais da Pessoa vital (e seus desejos, apetites, impulsos de natureza bio-psicológica básica - mais «fundos» mas mais elementares e indiferenciados. São estes pois o substracto e os alicerces das superestruturas anímico-espirituais que sobre ele assentam e se diferenciam nos novos sistemas mais diferenciados da consciência, do carácter, do intelecto - coroados como se tem insistido - pela Pessoa cultural. Trata-se portanto de sistemas funcionais mais livres e autónomos agindo em fluídas transacções recursivas com o ambiente sócio-económico, histórico-político e cultural, manifestando-se em atitudes espirituais (como tanto insistia Sérgio) de crítica, criatividade e independência pessoal - em liames relacionais íntimos com os outros homens - em fraterna cooperação, com intenções humanas, deveres cívicos, de coope-

${ }^{25}$ ) Joel Serrão, «António Sérgio, o Educador», O Tempo $e$ o Modo, 1969, pp. 69-70. 
ração, integração dos interesses colectivos para «o bem comum».

O Ser espiritual da Pessoa, assim constituído, embora se inspire de normas «ideais», não deixa de ficar ligado ao concreto da vida e do existir, estrutura-se como «real» - como organização anímico-espiritual pessoal, mas objectivando-se nas suas relações com o mundo envolvente na ordem social e da cultura.

- Estão aqui implícitos difíceis (e porventura contestáveis) nexọs epistemológicos que não é agora possível discutir.

- É neste quadro que se podem (ou não) manifestar e desenvolver sentimentos (e não só «ideias»), tendências de acção prospectiva no âmbito das relações inter-pessoais, grupais, comunitárias (até às nacionais) das quais resulta o comportamento, as atitudes e posições individuais e inter-individuais - que Sérgio se propunha «educar» para a melhor formação humana, para a democracia autêntica. Por uma Democracia humana - mas isso ficará para outra oportunidade.

Precisemos algo mais sobre as ciências da educação, vistas neste ângulo antropocientífico e voltemos ao modelo adoptado, comparando estas polaridades sócio-culturais do Homem a ser educado com as antinomias bipolarizadas que também distinguimos nas intervenções socioterápicas e psicoterápicas sobre o Homem perturbado.

Opusemos então na generalidade, as tendências de autonomia e as tendências de controlo, historicamente referidas a Rousseau e a Maquiavel.

Daí as antinomias polares na prática do lidar e cuidar dos homens enfermos, entre o animar/dirigir; entre o organizar/comandar; o comunicar/manipular. Dito na generalidade: ajuda humana, de uma banda, intervenções técnicas incisivas, de outra banda.

$\mathrm{Na}$ praxis opõem-se assim: 1) as atitudes de aceitação aberta, compreensiva e comunicativa e 2) a aplicação distanciada estandardizada - respectivamente: 1) de terapias (e porque não também de atitudes educativas?) de tipo compreensivo, humanístico («antropológicas») versus; 2) de terapias de tipo comportamentalista (na pedagogia até ao extremo das máquinas de ensinar/aprender?).

Sabe-se como estas polaridades correspondem às posições da psicologia e da psicopatologia (e também no caso, da pedagogia) de orientação compreensiva em contra-ponto com as correntes de base experimentalista, explicativa de cunho científico-natural (em algumas das quais a Psiqué é apenas um «epifenómeno»). 
Neste contexto é claro que as «pedras vivas» de Sérgio se incluem fundamentalmente do lado das atitudes espirituais correspondentes à autonomia, liberação, abertura e espontânea criação de actividades....

Na pregação e na praxis de Sérgio o fito era a instrução educativa, a formação de novas mentalidades, a procura até de qualidades novas nos homens de amanhã....

Note-se que não queremos igualar (nem reduzir) posições de recuperação do Homem perturbado e posições de desenvolvimento do Homem ineducado mas educável. Como temos mostrado, há porém muitas homologias, ou noutros casos apenas analogias, ambas muito significativas.

Na obra de Sérgio é clara esta ligação à praxis — não só educativa, como sócio-política democrática e económico-cooperativista.

Em vez de mais análises leiam-se os seus escritos: as «Cartas do Terceiro Homem», «Os Diálogos de Doutrina Democrática» e a «Alocução aos Socialistas»!

Sente-se neles o educador bem participante, no seu entusiasmo pelos sistemas de auto-governo das escolas, em assunção de iniciativas e responsabilidades pessoais - sempre em ligação com os outros, integrados no grupo, na comunidade social.

O «escândalo» (de valor positivo) de Sérgio estava no contraste com a educação "clássica», memoralista, dirigista, rígida - na sua campanha de autêntico apostolado pela dignificação do Humano.

Afinal não cuidava apenas do espírito, cultivava também da Saúde, da physis (um ponto muito discutido na sua obra) buscando a saúde activa pelos exercícios ginásticos, o melhor sustento e higiene corporal, etc.. E também, muito em especial, o adextramento manual, o exercitar da senso-motricidade, o treino dos instrumentos de fabricação agrícola e industrial, (os jardins, a oficina na escola!). Todas estas actividades concretas visavam a aquisição de técnicas de dextreza, de observação e execução —de experiência — repete-se - e não apenas com essa finalidade mas como meio para o «aprender a educar-se a si mesmo» em «formas» perceptivo-motoras e depois em formas cognitivas «inteligíveis»....

- Dito na sua globalidade. Do material - mediante o vital e o anímico - até ao espiritual!

Se se atentar nesta estratificação resolvem-se - na linha convergente da posição antropológica adoptada - alguns dos contrastes da obra de Sérgio - já não diríamos nos seus fundamentos filosóficos (idealismo crítico versus materialismo histórico e outros) mas, muito em especial, no que concerne 
a praxis humana da humanização de todos os instrumentos e técnicas de acção, em prol do melhor desenvolvimento do homem na realidade do seu viver, existir, agir e produzir.

Afinal nem tudo em Sérgio é racional - como Homem completo que foi. A «emotividade» - melhor os seus afectos e sentimentos, impulsos e tendências, o entusiasmo impetuoso para a acção educativa - impregnavam o conjunto da sua personalidade até ao nível do Espírito, em ideias «humanistas» e humanitaristas do mais alto quilate.

Entusiástico, hiperbólico mesmo - sim - mas, ao mesmo tempo, esclarecido e reflectido, buscando a Razão e a moral, se quiserem - uma moral racionalizada uma razão moralizada mas, na sua globalidade, um modo de ser plenamente humano.

- Não se contarão aqui muitas das «pedras vivas» de Sérgio para a construção de uma Antropologia?

Está em curso a reformulação de uma nova Antropologia, fazendo convergir as múltiplas ciências na sua referência à personalidade em situação concreta num mundo em rápido devir.

António Sérgio é dos poucos pensadores portugueses, em cuja «obra» continua a ser indispensável reflectir na edificação do saber e da sageza, na realização de uma praxis mais humana. $\mathrm{Na}$ sua ensinança e actos o «dever-ser racional» e o «dever-ser-uno» implicam também um «dever-ser-humano».

\section{NOTA A}

Ao contrário do que se supôs, não foi com o trabalho «Da natureza da afecção»" que Sérgio concorreu à Faculdade de Letras da Universidade de Lisboa. Consta do documento mandado publicar pelo Director J. M. de Queiroz Veloso que em 21 de Junho de 1912 entrou na Secretaria «um requerimento de António Sérgio de Souza pedindo para ser admitido a concurso para assistente da cadeira de filosofia da mesma Faculdade...»; vem acompanhado de quatro documentos e uma obra com o título "Notas sobre os sonetos e as tendências gerais da Philosofia de Anthero de Quental». Não há mais referências ao caso, pelo que se presume que Sérgio tenha desistido. A esta obra da sua adolescência, apresentada a Concurso e escrita sete anos antes (mas editada em 1908) se refere Sérgio logo no começo do seu célebre estudo sobre «Os Dois Anteros»- O luminoso e o nocturno» (Ensaios, Tomo IV).

Torna-se assim verosímil que o ensaio sobre a «afecção» tivesse sido um esforço (dos raros de tipo «académico») para «descer» ao nível do elementar, atomístico (fragmentado) o que - pelos escritos anteriores - era já contrário à sua posição pessoal - uma concessão sem par na sua obra.

Descontente, como mais tarde a maioria dos psicólogos, com tal orientação que desatendia a globalidade da vida psíquica, Sérgio retomou a linha «anteriana» do seu primeiro ensaio. 
Houve quem dissesse .que fôra a frustração deste malogrado concurso para a docência universitária uma das motivações das atitudes de auto-sobre valorização que por vezes exibia. Não acompanhamos tal interpretação psicodinâmica. Aliás, o próprio relutava èm fazer tais auto-análises e dizia-se desinteressado em geral de «miudarias biográficas». Evitava - podemo-lo confirmar como médico _ confidenciar as suas intimas motivações (excepto em cartas mais íntimas).

\section{NOTA B}

Q Dicionário Biográfico Universal de Autores, Vol. IV Lisboa: SERGIO de Souza Junior, António, por Lopes Rodrigues, dá notícias da sua ida para o Rio de Janeiro (1919). Empreende então com Álvaro Pinto a gestão de uma tipografia, o que acabou em «desastre comercial», ficando Sérgio «bastante enfermo» com uma crise, depressiva na qual, como mais tarde no fim da vida, afirmava que «não voltaria mais a escrever» (uma ideia tipicamente melancólica de renúncia à actividade e falta de confiança e incapacidade). Esteve em tratamento numa Casa de Saúde na Floresta Negra e já em 29-XII-1921 - escrevia em carta a Vianna da Motta-dando-o «aparentemente como o mesmo", já vivo, interessado e conversador, como era habitualmente. Nos anos seguintes tem grande operosidade (Biblioteca Nacional, etc. em 1923, Ministro da Instrução Pública, criador dá «Junta de propulsão dos Estudos» precursora da Junta de Educação Nacional).

Referem-se estes dados como exemplos da viragem da depressão inibitória das suas actividades para a sua forma habitual de ser, pujante de iniciativas e realizações de ordem cultural que não suspende mesmo durante as suas-prisões por motivos políticos. Para mais pormenores (loc. cit., nota 1); «Personalidade e atitude espiritual» (pag. 55-101).

\section{NOTA C}

Não é necessário sublinhar que a vigas mestras deste nosso projecto de referência : antropológica da obra de Sérgio assentam nos modelos da personalidade em situação e da psiçopatologia e de Saúde mental que desde 1957, temos vindo a formular (V. Barahona Fernandes - «Da Psiquiatria para a Saúde Mental - Um modelo antropológico. médico», Saúde Mental, n. ${ }^{\circ}$ 31-32, Lisboa 1977 e respectiva bibliografia; V. versões in Arch. Psych. Nervenkrank, 229, 53-73 e Actualités Psychiatriques, 6, 1930, Paris).

Para apoio do texto, lembremos apenas o seguinte:

-A personalidade é uma complexa organização estrutural na qual- os diferentes sistemas funcionais se dispõem num todo centrado sobre o próprium (Eu) e cuja textura se não pode dissociar nem sepatar- da situação ambiencial, composta esta também de modo complexo, desde as condições fisico-quimicas e biológicas (ambiente eco>lógico e habitacional) até ao contexto sócio-histórico-cultural, às relações humanas, ao mundo dos saberes e das técnicas. Nesta organização da Personalidade há que diferenciar as estruturas básicas, as superestruturas e respeetivos sistemas funcionais e, além disso, os processos estruturantes do desenvolvimento e as organizações globalizantes integrativas. 
€omo estruturas básicas consideramos: 1) o organismo (conjunto: dos órgãos e sistemas somáticos, incluindo o sistema nervoso)* 2) a eorporalidade (esquema corporal e sua vivência, processos de relação psicossomática, psico-sensoriais, psico-motores, psico-vegetatives), 3) o fundo endotímico-vital (sistema psico-biológico sobre- estruturando as duas primeiras instâncias e desenvolvendo-se ao nível afectivo, instintivo e conativo básicos); compreende-o humor, as pulsões primárias, a iniciativa e a espontaneidade da actividade, aquilo a que se chama elan, vital óu empuxo (corresponde ao ânimo* ao temperamento), e 4) a vigilidade (mecanismo básico do sono e do estar acordado e graus intermedios).

As superestruturas incluem: 5) o carácter e 6) o intelecto, dizendo respeito aos processos afectivos-conactivos e aos aspectos cognitivos, a um nivel superior, mais diferenciado e, ainda, 7) o ser espiritual pessoal organizado como pessoa cultural, - os valores, apreciações e significações pessoais, normas éticas, estéticas e juridicas, sentimentos espirituais, juízos reflexivos e criativos.

Dos processos estruturantes genéticos registam-se: 8) a reactibilidade dinâmica e 9) -a aprendizagem; são estruturas que se organizam no curso da evolução e que estão respectivamente relacionadas com o carácter e o intelecto.

As organizações globalizantes são: 10) a consciência - integração no presente de todas as actividades psíquicas actuais com base na vigilidade e que se organiza em diferentes níveis,- desde a consciência ^dos objectos do próprio (Eu) até à consciência transcendente, ligada à Pessoa cultural; na organização da consciência está implícita a noção de inconsciência (o dito «inconsciente») dos processos psico-biológica, nas várias etapas da vida; 2) da reactibilidade dinâmica aos se tornam latentes (por regressão, esquecimento e outros processos).

Numa posição central está o Proprium, o cerne íntimo da Personalidade, que sintetiza e organiza, de modo "pessoal», globalizando no decorrer da evolução biográfica do indivíduo, o conjunto dos outros sistemas funcionais, estruturados através: 1) da maturação organo-biológica, nas várias etapas da vida 2) da reactibilidade-dinâmica aos encontros .e relações pessoais e 3) da aprendizagem proporcionada pelas técnicas e pelo ambiente ecológico e sócio-cultural. Nessa base dá-se então a socialização e aculturação personalizadas na Pessoa cultural.

Estas instâncias representam categorias de sistemas funcionais inter-relacionadas dialecticamente e estratificadas hierarquicamente; caracterizam-se por estarem, de certo modo, integradas, sem deixar de gozar de certa autonomia; evoluindo no tempo, as instâncias básicas são, no entanto, mais fixas, as superiores mais fluidas, permanecendo sempre o. todo em interacção dos seus constituintes e, em especial, com os diferentes modos componentes da situação ambiencial, também igualmente inter-relacionados.

\section{NOTA D}

Numa edição do Autor (sem data, Portugália, Lisboa) : Um problerna anteriano (sobre a ideia e a realidade do desprendimento activo na peregrinação moral do autor dos sonetos " - um «pequeno ensaio» destinado ao grande público, constroi Sérgio um curioso «diá^ logo na praia» entre quatro, interlocutores no qual, bordando leves pinturas literárias do ambiente, resume o problema enunciado, acentuando o já dito nos Ensaios. O «desprendimento» é aqui explanado na forma como Antero o entendia na prática dos budistas, vitta na 


\section{Antonio Sérgio}

imaginação dos românticos alemães do século XIX. Digna de nota é a necessidade, que acentua, de complementaridade a) da «Razão» objectivada e externa, e b) da interioridade do pensar reflexivo, por «obra centripeta de reflexão auto-crítica» - uma obra do espírito sobre o próprio espírito dos juízos intrínsecos da consciência humana - obtida, (insiste Sérgio), mediante o «desapego do sensível».

Na dedicatória autografada do exemplar que possuímos, espelha-se como sempre na vida pessoal sergiana, a sua afectividade: «lembrança e homenagem amiga do A. S., a seguir ao nome do A. e de sua mulher (aposto de «...zinha») que lhe era usual no convívio íntimo. Um exemplo do «humano» em Sérgio, que por um esforço desejava, na teoria, tornar «racional».

\section{NOTA E}

Repetimos aqui o espanto e protesto da não difusão fora de Portugal da posição criticista da obra de Sérgio, até hoje, do nosso conhecimento, ainda não traduzida noutras línguas! - Ou não haverá nela nada de verdadeiramente original merecedor de difusão internacional?

De facto, as suas luminosas e criadoras «pedras vivas» não puseram em marcha aquele movimento de organização da «teia de ideias» de que fala nas Cartas de Problemática, e a sua globalização no todo, no «uno», apenas enunciado e jamais (será possível?) formulado e definido.

Não foi um filósofo sistemático como dissemos. A sua teia conceptual foi-se formando na praxis da acção pedagógica, moral e política, sempre em resposta «dialéctica» (dizemos nós, embora Sérgio recusasse a forma como tal conceito era usado pelos chamados materialistas dialécticos, o que para ele era uma contradição insuperável). Em constante peleja com todas as correntes que iam emergindo em Portugal (desde os liberais republicanos até aos autocratas salazaristas, desde os positivistas aos espiritualistas teológicos ou sentimentais) Sérgio dispersou as suas geniais reflexões de modo coerente mas sem formular a sua mais sistemática estruturação. É o que estamos esboçando mediante a complexa referência das suas «pedras vivas» ao conjunto da personalidade no sentido da edificação de uma futura antropologia filosófica.

\section{NOTA F}

V. o exemplo que damos a pp. 107-108 [loc. cit. O] acerca do conceito exterior/interior e das categorias dependência/independência.

Esta luta em muitas frentes que Sérgio traçou quase toda a sua vida, com o correr do tempo, ia-se tornando cada vez mais difícil e complexa.

Após a abordagem já referida do atomicismo psicológico e sensismo conceptual, virou-se contra o positivismo naturalista a que opunha uma espécie de axiomatia matematizante; fincou-se depois na pugna contra o intuicionismo bergsoniano e todos os irracionalismos. Muito em especial frente às mitofilias, no seu dizer, "pseudofilosofantes». Não vale insistir na sua rejeição, resistência ou mera não absorção das novíssimas correntes surgidas nos anos 40-50 e em especial nos anos de convalescença da melancolia sofrida em 1959-60, já em avançada idade. Em conversas pessoais com Sérgio (loc. cit. p. 196) demos conta das suas críticas, por exemplo ao existencia- 
lismo e depois às versões divulgadas do materialismo dialéctico - que tanto o contrariavam, còmo um dos primeiros entre nós a ter ousado utilizar os seus aspectos históricos e económicos nos seus famosos estudos sobre a História e Geografia de Portugal.

- «A arte é longa e a vida breve» e todo o devir do intelecto e da invenção de novas formas têm — como a vida - um limite.

Pude éntão compreender Sérgio nessas dificuldades, agravadas por um certo desânimo pós-melancốlico. Mais do que «doente» apresentavã-se então como espiritualmente reservado e «desencantado» (p. 90, loc. cit.).

Não se conclua destas linhas, como já insistimos que haveria então qualquer deterioração mental. Como é regra nas melancolias endógenas, a remissão deixou o intelecto intacto - plenamente capaz dt 1er os novos livros que lhe ofereciam e de os apreciar com a mesma «lucidez», embora com muito menos entusiasmo e sem o empuxo para os criticar em novos escritos, muito menos polemizantes. 